\title{
Niche engineering reveals complementary resource use
}

\author{
Jacob T. Gable, ${ }^{1}$ David W. Crowder, ${ }^{1,4}$ Tobin D. Northfield, ${ }^{2}$ Shawn A. Steffan, ${ }^{3}$ and William E. Snyder ${ }^{1}$ \\ ${ }^{1}$ Department of Entomology, Washington State University, Pullman, Washington 99164 USA \\ ${ }^{2}$ Department of Zoology, University of Wisconsin, Madison, Wisconsin 53706 USA \\ ${ }^{3}$ USDA-ARS, Department of Entomology, University of Wisconsin, Madison, Wisconsin 53706 USA
}

\begin{abstract}
Greater resource use by diverse communities might result from species occupying complementary niches. Demonstrating niche complementarity among species is challenging, however, due to the difficulty in relating differences between species in particular traits to their use of complementary resources. Here, we overcame this obstacle by exploiting plastic foraging behavior in a community of predatory insects common on Brassica oleracea plants in Washington, USA. These predators complemented one another by partitioning foraging space, with some species foraging primarily along leaf edges and others at leaf centers. We hypothesized that emergent biodiversity effects would occur when predators partitioned foraging space on leaves, but not when spatial complementarity was dampened. Indeed, on intact leaves, edge- and center-foraging predators combined to kill more prey than any single predator species could by itself. These emergent diversity effects, however, disappeared on plants damaged by the caterpillar Plutella xylostella. Caterpillar chew-holes brought edge habitats to the center of leaves, so that all predator species could attack aphids anywhere on plants. With spatial niche differences diminished, there were no benefits of predator diversity; the most voracious single predator species killed the most aphids. Thus, caterpillar herbivory determined whether multi-predator-species effects reflected complementarity or species' individual impacts. Our study provides direct evidence for a causative relationship between niche differentiation and increased resource consumption by diverse communities, as revealed by ecological engineers that homogenize the foraging environment.

Key words: biodiversity effects; Brassica oleracea; cabbage aphid predators; complementary niches; complementarity; field and greenhouse experiments; habitat complexity; identity effect; niche overlap; niche partitioning; Plutella xyostella; Washington state, USA.
\end{abstract}

\section{INTRODUCTION}

Across a broad range of ecosystems, increasing the number of consumer species increases the volume of resources consumed (Hooper et al. 2005, Cardinale et al. 2006). This is predicted to occur when different species use dissimilar subsets of the total resource pool, so that species combine to access more resources that any single species could on its own (MacArthur 1958, Hutchinson 1959). That is, species occupy complementary niches. A causal link between resource-use differences and resulting diversity effects has been surprisingly hard to demonstrate, however, because of the inherent difficulty in manipulating species' resource-use niches independent of other species traits (Finke and Snyder 2008). For example, species differ from one another in body size, metabolic rate, and a host of other traits that are manipulated along with feeding habits whenever species richness is varied (Huston 1997, Loreau and Hector 2001). Thus, ecologists have struggled to differentiate between species-identity effects, and true complementarity, as the underlying causes of greater resource use

Manuscript received 2 February 2012; revised 30 April 2012; accepted 7 May 2012. Corresponding Editor: J. T. Cronin.

${ }^{4}$ Corresponding author. E-mail: dcrowder@wsu.edu by diverse compared with simple communities (Naeem and Wright 2003, Cardinale et al. 2006).

One approach to examine complementarity is to determine whether ecological functions in diverse communities exceed the expected performance of the strongestacting individual species (Petchey 2003). However, this approach provides no insight into the mechanisms that lead to emergent diversity effects (Petchey 2003). A more direct test is to experimentally manipulate niche complementarity independent of species identity. For example, when consumers have flexible resource needs and acquired food preferences, species can be "trained" to use the same or different resources (Finke and Snyder 2008). Another possibility exists when species differ in where they forage in the environment, such that each species can only access resources available in the habitat it frequents. Here, habitat complexity could be experimentally manipulated to heighten or lessen spatial niche differences, while measuring how this impacts diversity effects, as a means to uncover any relationship between niche partitioning and community-wide resource use (Griffin et al. 2009). An advantage of this approach is that it might unveil diversity effects as they naturally vary across ecosystems and landscapes, with species complementing one another in some situations but filling redundant roles in others. 
Here, we explored interrelations among habitat complexity, niche complementarity, and biodiversity effects in a community of cabbage aphid (Brevicoryne brassicae) predators (Aphidius matricariae wasps, Diaeretiella rapae wasps, Hippodamia convergens beetles, Nabis alternatus bugs) foraging on Brassica oleracea plants. These predators clearly differ both in inherent voraciousness, fostering strong species-identity effects, and in where they hunt on leaves, fostering complementarity (Fig. 1A). Diverse communities of these predators kill far more aphids than any single predator species (Snyder et al. 2006, Straub and Snyder 2008, Northfield et al. 2010), consistent with space-use complementarity leading to emergent diversity effects. A causal link between the two, however, has never been directly demonstrated. The aphids and their predators often cooccur with Plutella xylostella caterpillars, which chew ragged holes in leaves (Steffan and Snyder 2010). The aphid predators almost never eat caterpillars (Steffan and Snyder 2010). Nonetheless, caterpillar feeding could disrupt space-use differences among aphid predators, if predator species otherwise restricted to leaf edges can use holes chewed by caterpillars as "toe holds" providing access to aphids in leaf centers (Fig. 1B). This led us to hypothesize that caterpillar feeding could dampen spatial niche separation among predators by providing edge-like habitats throughout leaves (Fig. 1B). In turn, reduced niche differences might diminish the benefits of predator diversity for aphid suppression seen on plants with intact leaves.

\section{Methods \\ Caterpillar impacts on predator-aphid relationships in the open field}

In an open-field setting in Washington (USA) we first tested whether positive effects of predator diversity on aphid consumption would diminish with increasing caterpillar densities, based on our hypothesis that caterpillar feeding would reduce spatial complementarity among predators. To accomplish this, we used sprays of Bacillus thuringiensis (Bt) insecticides to reduce caterpillar densities in five $25-\mathrm{m}^{2}$ plots of B. oleracea plants; five remaining $25-\mathrm{m}^{2}$ plots were sprayed with water (as a harmless control) so natural caterpillar populations developed (detailed in the Appendix: Fig. A1). Bt is toxic to Lepidoptera but leaves other species unharmed (Talekar and Shelton 1993; Appendix: Fig. A2). On 7 and 23 July 2009 we visually searched 10 plants in each plot for aphids, caterpillars, and predators (detailed in the Appendix).

\section{Impacts of caterpillar damage on predator-niche overlap}

In a second open-field study in Washington (USA) we conducted observations of predator foraging behavior to test the hypothesis that caterpillar feeding would dampen spatial complementarity between predators. We established four $4-\mathrm{m}^{2} B$. oleracea plots; two were sprayed with Bt insecticide to exclude caterpillars, and two were sprayed with water as a control (detailed in the Appendix). On 29 July, 5 August, and 10 August 2011, we visually scanned plants in each plot for 15 minutes each hour, from 11:00 until 15:00 hours. We recorded the species of all predators observed, whether they were foraging along the leaf perimeter or in the leaf center (with leaf center defined as being $>5 \mathrm{~mm}$ from the perimeter), and whether the predator was near any leaf edge (within $5 \mathrm{~mm}$ of the perimeter or an interior edge created by caterpillar feeding) (detailed in the Appendix). From all plots, leaves were collected to measure total leaf area, leaf perimeter area, and total leaf edge area (the total area within $5 \mathrm{~mm}$ of all natural or caterpillar-created edges, detailed in the Appendix).

\section{Caterpillar damage and predator diversity effects}

Our field experiments allowed us to examine how caterpillars impacted predator-aphid relationships in natural communities, and to observe how caterpillar feeding mediated space use by predators. These studies, however, could not convincingly draw a causal link between any differences in spatial niches that caterpillar feeding engenders, and the importance of species-rich predator communities for aphid suppression. To fill this gap we performed an experiment in greenhouse mesocosms, where we conducted a fully factorial manipulation of two factors: predator species richness $(0,1,2$, or 4 species) and caterpillar feeding damage (present or absent).

Caterpillar damage was established by allowing 10 third-instar P. xylostella caterpillar larvae to feed for 72 $\mathrm{h}$; caterpillars were then removed before predators or aphids were added. Predators were manipulated within a substitutive design, such that four individuals were present in each cage (except for controls), and all possible combinations of our four predator species were included at each level of predator richness (detailed in the Appendix). To begin the experiment, 20 aphids were released into all mesocosms and allowed $72 \mathrm{~h}$ to establish, after which we performed initial aphid counts and released predators. Predators were allowed to feed for $72 \mathrm{~h}$, after which we conducted final aphid counts. The number of aphids that had been parasitized during the 72-h period was determined by allowing parasitoid larvae to develop in their aphid hosts for 10 days after predator removal, at which point the number of parasitized aphids were counted (this number was subsequently subtracted from the final aphid count). The experiment included two temporal blocks, initiated on 15 and 22 October 2010, and included 144 experimental units total (detailed in the Appendix). We again observed predator foraging behavior on both caterpillar-damaged and undamaged plants, as described for the open-field experiment (detailed in the Appendix).

\section{Statistical analyses}

We analyzed aphid counts from the open-field experiment using a generalized linear model with a

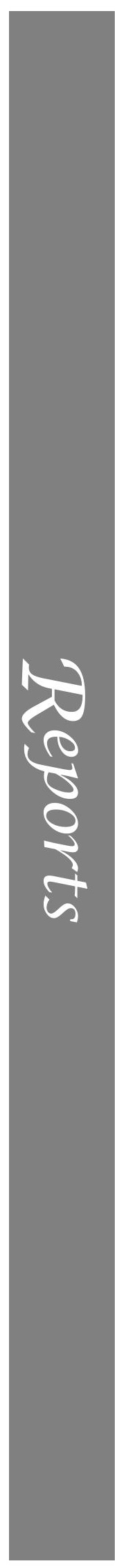



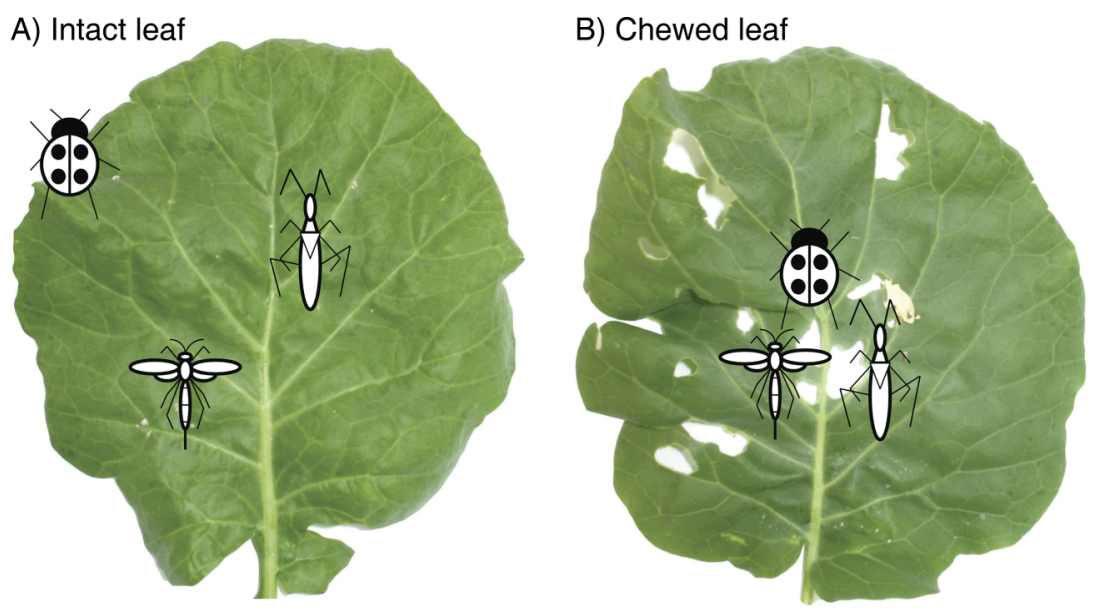

FIG. 1. At our study site, cabbage aphids are attacked by the lady beetle Hippodamia convergens, the predatory bug Nabis alternatus, and the endoparasitoid wasps Aphidius matricariae and Diaeretiella rapae. The lady beetle forages primarily at leaf edges, whereas the smaller wasps and predatory bug commonly hunt at leaf centers (Straub and Snyder 2008). (A) On undamaged leaves the predator species will clearly partition foraging space, such that they occupy relatively distinct space-use niches. (B) However, by providing edge-like habitats in leaf centers, caterpillar feeding damage might diminish space-use differences among predators.

negative binomial distribution (PROC GENMOD; SAS Institute 2012b), including the factors caterpillar density (high vs. low), predator species richness, and their interaction. In this analysis, data were pooled across sample dates to account for temporal variation and nonindependence of aphid and predator counts over time; we assumed an underlying negative binomial error distribution to account for over-dispersion and heteroscedasticity in the data. For the greenhouse study, we examined change in aphid abundance [ln(final/initial abundance)] using ANOVA including the factors: number of predator species, caterpillar feeding (present or absent), temporal block, and all two-and three-way interactions. To further examine these data, we used ANOVA followed by least significant difference tests to assess whether change in aphid abundance in the fully diverse treatment (with four species) differed from the monocultures; this allowed us to detect if transgressive overyielding occurred (Snyder et al. 2006).

For field and greenhouse behavioral observations, we used logistic regression to examine whether the proportion of predators foraging in the center vs. perimeter of leaves, and the proportion foraging along any leaf edge, were affected by the factors: caterpillar presence or absence, predator species ( $H$. convergens or $D$. rapae), and their interaction. For these tests, each cage or field plot served as a replicate, with individual observations serving as the counts. For leaves collected from both the field and greenhouse, we compared leaf area (log transformed) and the proportion of edge area (logittransformed) from caterpillar-damaged vs. undamaged leaves, using two-way ANOVAs that included block effects. The general linear model was analyzed using SAS, all remaining analyses were performed using JMP (SAS Institute 2010a, $b$ ).

\section{RESULTS}

\section{Caterpillar impacts on predator-aphid correlations in the open field}

We found a significant interaction between caterpillar density and predator species richness in open-field plots $\left(\chi^{2}=1.34, P=0.044\right.$; Fig. 2A; Appendix: Table A1). Aphid densities increased as predator richness increased when caterpillar densities were naturally high, but there was a flatter relationship between aphid densities (declining slightly) and predator richness when caterpillar densities were experimentally reduced (Fig. 2A; Appendix: Figs. A1, A2).

\section{Impacts of caterpillar damage on predator niche overlap}

Two predator species, the ladybeetle $H$. convergens and the parasitoid wasp D. rapae, were observed frequently enough to allow their behavior to be statistically analyzed. On plants in plots where caterpillars were excluded, so that leaves were intact, lady beetles foraged more frequently along leaf perimeters than in leaf centers ( $n=941$ observations; $\chi^{2}=56.9, P<$ 0.0001 ), while wasps foraged most frequently in leaf centers ( $n=941$ observations; $\left.\chi^{2}=85.5, P<0.0001\right)$; thus, foraging by these two species was largely separate in space (Fig. 2C; Appendix: Table A2). The pattern was very different on plants that had been fed upon by caterpillars. With edges available in leaf centers, lady beetles readily foraged there, significantly diminishing space-use differences between lady beetles and wasps (species $\times$ caterpillar interaction: $n=941$ observations; $\chi^{2}=4.58, P=0.032$ ) (Fig. 2C). Caterpillar feeding significantly increased the total edge area on leaves (Appendix: Fig. A3A). However, caterpillars did not significantly alter total leaf area, possibly because 

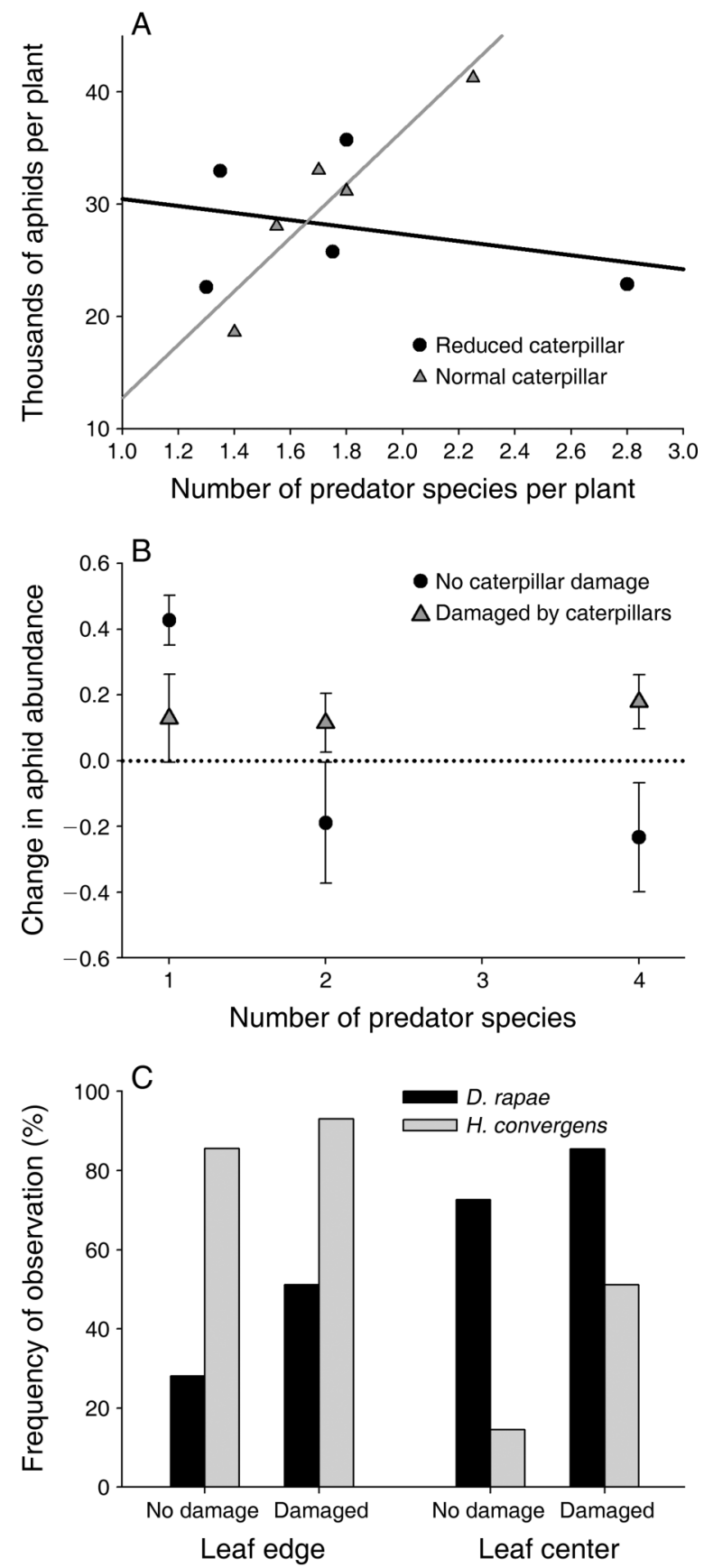

FIG. 2. In both (A) open field Brassica oleracea plantings and (B) greenhouse mesocosm cages, aphid densities decreased with increasing predator richness when caterpillar feeding damage was reduced or absent (black solid circles and line), but not when caterpillar feeding damage was present (gray triangles and gray line). In panel (B) data are means \pm SE. Similarly, (C) spatial complementarity among Diaeretiella rapae wasps and Hippodamia convergens beetles was significantly reduced on caterpillar-damaged leaves ("damaged"), as the frequency of foraging in leaf centers for the two species was more similar when caterpillars were present than when they were absent ("no damage") (species $\times$ caterpillar interaction, $n$ $=941$ observations; $\chi^{2}=4.58, P=0.032$; Appendix: Table A3). damaged $B$. oleracea plants exhibited compensatory growth (Appendix: Fig. A3B).

\section{Caterpillar damage and predator-diversity effects}

When we conducted a factorial manipulation of caterpillar feeding damage and predator species richness, we found that chew holes dramatically altered the relationship between predator species richness and aphid suppression (caterpillar $\times$ richness interaction: $F_{2,116}=$ 4.78, $P=0.010$, Fig. 2B, Appendix: Table A3). When plants were undamaged, aphid suppression increased with increasing predator species richness (Fig. 2B). However, on caterpillar-damaged plants there was no change in aphid suppression with increasing predator species richness (Fig. 2B). Thus, feeding damage by caterpillars eliminated the predator-diversity effect. On undamaged plants, each single predator species killed significantly fewer aphids than the diverse mix of four predator species (Fig. 3A, Appendix: Table A4). However, on caterpillardamaged plants single species variously killed more, the

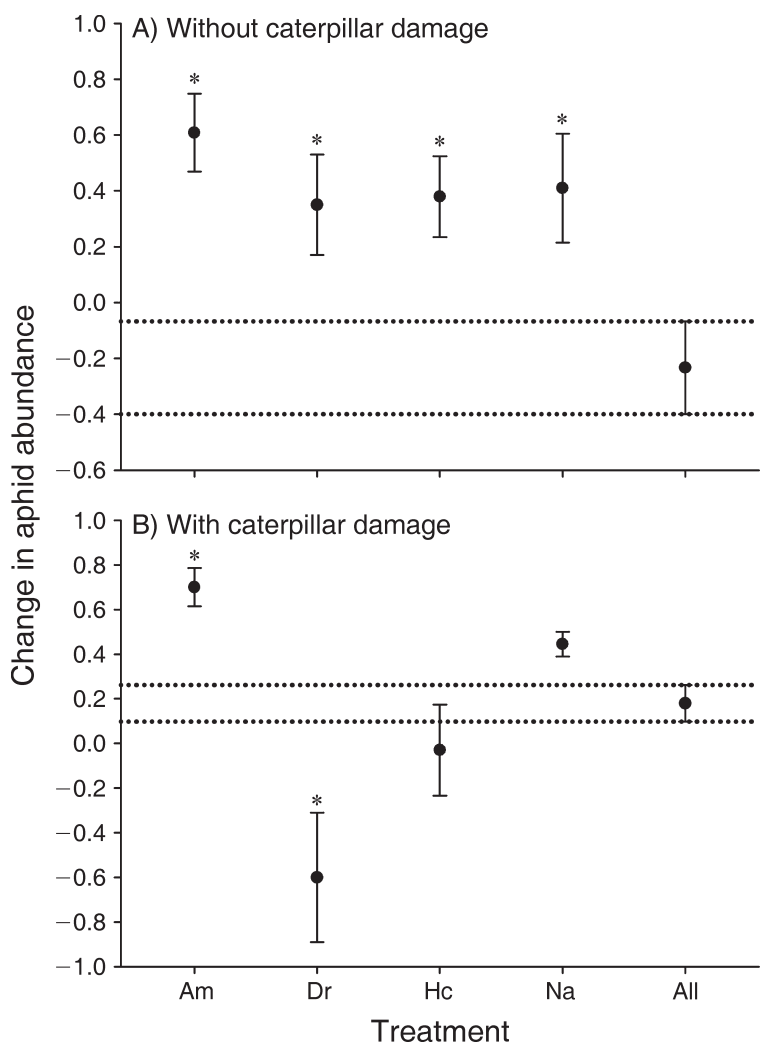

FIG. 3. Change in aphid abundance (mean $\pm \mathrm{SE}$ ) when aphids were exposed to single predator species (Am, Aphidius matricariae; Dr, Diaeretiella rapae; Hc, Hippodamia convergens; $\mathrm{Na}$, Nabis alternatus) or a diverse, four-species, predator community on plants (A) without and (B) with caterpillar damage. The dotted lines indicate the mean $\pm \mathrm{SE}$ for the diverse community; asterisks indicate a significant difference between single-species and diverse community $(P<0.05)$ (Appendix: Table A4). 


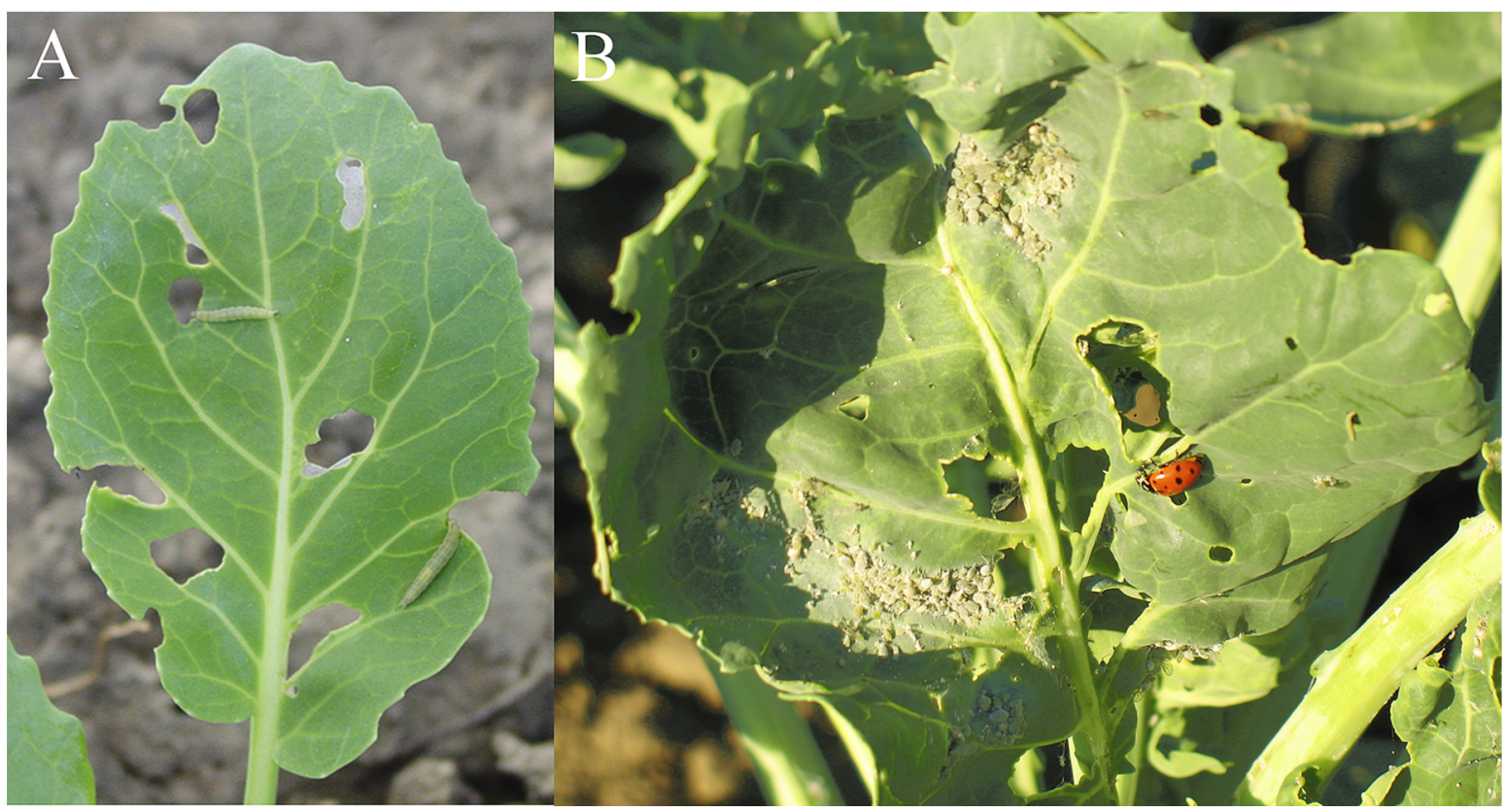

Plate 1. (A) Plutella xylostella caterpillars chew ragged holes in Brassica oleracea leaves, which (B) lady beetles use as toeholds to access aphids in leaf centers that the predators would otherwise be unable to reach. Photo credits: S. A. Steffan.

same, or fewer aphids than did diverse predator communities (Fig. 3B, Appendix: Table A4).

Caterpillar feeding damage did not directly influence aphid abundances in the absence of predators (Appendix: Fig. A4). While caterpillar feeding significantly increased edge area on leaves, as in the open-field this occurred with no significant change in total leaf area (Appendix: Fig. A5). Averaging across all predator richness treatments, predators similarly reduced aphid abundance on plants with or without caterpillar feeding damage (Appendix: Fig. A6, Table A5). The effects of caterpillar feeding on predator foraging behavior, and leaf architecture, were similar in the greenhouse to what was observed in the field (Appendix: Figs. A7 and A8, Table A6).

\section{Discussion}

Across open-field and cage studies, caterpillars controlled whether predators exerted complementary or substitutable impacts on aphids. Where caterpillar feeding damage was reduced or absent, aphid densities declined with increasing predator species richness (Fig. 2). This suggested strong predator complementarity, where different predator species made unique contributions such that several predator species were needed to maximize aphid suppression. In stark contrast, in the presence of caterpillar feeding damage, increasing the number of predator species provided no benefit for aphid suppression (Fig. 2). This suggested that different predator species did not attack aphids in unique ways on plants chewed by caterpillars, so that a single, highly voracious predator species could maximize aphid suppression. Thus, caterpillar feeding eliminated the emergent diversity effects that were seen on undamaged plants.

We had hypothesized that caterpillars might dampen niche differences among predator species by chewing edge habitat into leaf centers, thereby homogenizing predators' space use (Fig. 1). Our observations of behavior suggested that this was indeed the case. In both the field and greenhouse, lady beetle foraging on undamaged plants occurred almost exclusively along leaf perimeters (Fig. 2C; Appendix: Fig. A7). On the other hand, wasps foraged most frequently in leaf centers, such that on intact leaves wasps and lady beetles foraged in different (and complementary) locations (Fig. 2C). When caterpillar feeding provided lady beetles with toeholds at leaf centers, however, they readily exploited this foraging opportunity and spatial overlap between beetles and wasps increased (Fig. 2C). Thus, the weakening of diversity effects we observed on caterpillar-damaged plants that suggested reduced complementarity, occurred concurrently with an observed decline of complementary space use. This strongly suggests a causal link between diminishing spatial niche divergence and a resulting weakening of consumer diversity effects. Caterpillars increased total edge area of leaves without changing total leaf area (Appendix: Figs. A3, A5, and A8), and did not significantly alter the overall ability of predators to suppress aphid abundance (Appendix: Fig. A6). Thus, caterpillars altered predator diversity effects without altering the overall effectiveness of predators.

Careful consideration of the results of our greenhouse-cage experiment provides further evidence that 
caterpillar damage mediated whether predators complemented one another. On undamaged plants, no single predator species killed as many aphids as the diverse mix of four predator species (Fig. 3A, Appendix: Table A4). This indicated that emergent biodiversity effects (i.e., transgressive overyielding, Petchey 2003) occurred when caterpillar damage was reduced or absent. However, the pattern was markedly different on plants that had been damaged by caterpillars. Here, different species killed fewer (A. matricariae), more (D. rapae), or the same $(H$. convergens, $N$. alternatus) number of aphids as did the four-predator-species mix. Indeed, the combined impact of the four predator species together reflected a simple averaging of what each predator species killed on its own (Fig. 3B; Appendix: Table A3). Thus, speciesidentity effects predominated. In this case, the performance of multi-predator-species mixes could be predicted based on the number of aphids each predator killed when that species occurred alone, and aphid suppression was maximized when the single most-effective predator species (the parasitoid wasp D. rapae) was by itself. The increased effectiveness of $D$. rapae when caterpillars were present may be due to their use of feeding holes; we observed that adult wasps used holes to move between leaf undersides and leaf tops (J. T. Gable and S. A. Steffan, personal observations). This perhaps allowed adult parasitoids to forage and access aphids across the entire leaf surface more effectively than when feeding holes were absent. Altogether, these results provide further evidence that caterpillars triggered a shift from predators complementing one another to exerting substitutable effects on the prey resource.

Our results differ from predictions of Schmitz (2007), who developed a general framework for predicting the impacts of multiple predator species on shared prey. Under that scheme, when multiple predator species are spatially separate but prey cross both predators' "domains," predators are predicted to exert substitutable effects, and increasing predator diversity will not increase prey consumption. This spatial arrangement of predators and prey occurred on intact leaves in our system, but we observed super-additive, rather than substitutable, diversity effects (Fig. 2). Under the Schmitz framework, when predators and prey all fully overlap in space, predators are predicted to interfere with one another, such that herbivore suppression decreases as predator diversity increases. In our system, this scenario occurred on caterpillar-damaged leaves, but we observed predator substitutability rather than predator-predator interference (Fig. 2). We suggest, however, that two small tweaks can bring our results entirely in line with the predictions of Schmitz (2007). First, Schmitz (2007) imagined mobile herbivores, such as grasshoppers, that readily redistribute themselves among the habitat domains of different predator species. In contrast, the aphids in our system are relatively immobile and can only be fully suppressed when predators can reach aphids everywhere that the herbi- vores occur (Northfield et al. 2010). Thus, herbivore mobility must be considered as an additional diagnostic factor. Second, Schmitz (2007) imagines predators that frequently engage in intraguild predation, such as spiders, so that interference is inevitable when predators' spatial domains overlap. In our predator community, however, intraguild predation (which could occur when predators feed on one another or parasitized aphids) appears to be less of a risk than cannibalism (Takizawa and Snyder 2011), so that predators would suffer little harm from being nestled among heterospecifics on caterpillar-damaged leaves. Thus, we must include the level of predator aggression to correctly predict that spatially homogenous predators will exert substitutable, rather than disruptive, effects.

There is growing realization that species may complement one another in one ecological context, but not in others (Loreau et al. 2003, Cardinale et al. 2007, Zavaleta et al. 2010, Isbell et al. 2011). In our system the factor that mediated complementarity was the presence of a species that altered the foraging environment, leafchewing caterpillars. "Ecological engineers" such as our caterpillars are known to impact biodiversity by increasing habitat complexity, expanding the resource base, and/or altering the behavior of other species, such that a broader range of species can be supported (Wright et al. 2002, Lill and Marquis 2003). The example presented here shows that ecological engineers can also impact whether species complement one another. Our open-field observations suggested that this flexibility in whether predators complement one another or not (Fig. 2), might lead to a mosaic of emergent diversity effects arising and disappearing across landscapes depending on whether caterpillars happen to be present or absent. Indeed, these results link findings from a series of previous experiments in this system where caterpillars were not included (e.g., Snyder et al. 2006, Straub and Snyder 2008, Northfield et al. 2010; but see Steffan and Snyder 2010) to the broader range of ecological conditions expected in the field.

Although studies have demonstrated positive effects of biodiversity on a wide variety of ecological functions (Hooper et al. 2005, Cardinale et al. 2006), few have convincingly demonstrated a causal link between niche differences among species and emergent biodiversity effects (Finke and Snyder 2008). The central difficulty lies in the fact that highly diverse communities are both more likely to bring together species that complement one another, and to include single highly impactful species. This problem is roughly analagous to earlier difficulties in relating differences among species in particular traits, to their ability to coexist through niche partitioning (Strong et al. 1979, Simberloff and Boecklen 1981). We overcame these obstacles by manipulating differences among consumer species along one niche axis, degree of overlap in foraging-space use, while simultaneously and independently manipulating species richness. This approach provided support for the

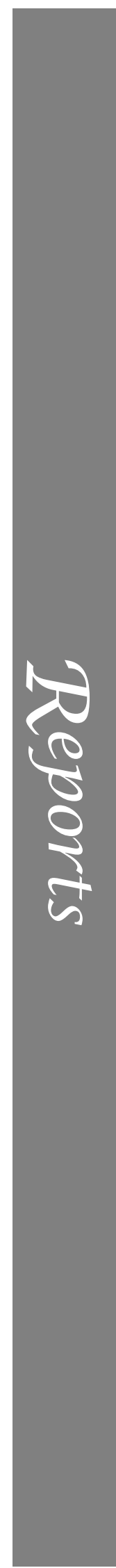


idea that it is differences among species in the resources they use that intensifies overall resource exploitation at higher levels of consumer biodiversity (Silvertown et al. 1999, Finke and Snyder 2008). Furthermore, our results strengthen the assertion that manipulating plastic foraging behavior to alter niche breadth among animal consumers is a particularly powerful approach to vary resource-use patterns independent from other aspects of species identity and diversity (Finke and Snyder 2008, Griffin et al. 2009). When this is accomplished through the deployment of ecological engineers, as we have done, such studies might also reveal how diversity effects naturally vary with ecological context.

\section{ACKNOWLEDGMENTS}

We thank Tadashi Takizawa and Elizabeth Aultman for aiding with the open-field surveys. This project was supported by USDA-NIFA grants number 2004-01215 and number 2007 02244.

\section{Literature Cited}

Cardinale, B. J., D. S. Srivastava, J. E. Duffy, J. P. Wright, A. L. Downing, M. Sankaran, and C. Jouseau. 2006. Effects of biodiversity on the functioning of trophic groups and ecosystems. Nature 443:989-992.

Cardinale, B. J., J. P. Wright, M. W. Cadotte, I. T. Caroll, A. Hector, D. S. Srivastava, M. Loreau, and J. J. Weis. 2007. Impacts of plant diversity on biomass production increase through time because of species complementarity. Proceedings of the National Academy of Sciences USA 104:1812318128.

Finke, D. L., and W. E. Snyder. 2008. Niche partitioning increases resource exploitation by diverse communities. Science 321:1488-1490.

Griffin, J. N., S. R. Jenkins, L. Gamfeldt, D. Jones, S. J. Hawkins, and R. C. Thompson. 2009. Spatial heterogeneity increases the importance of species richness for an ecosystem process. Oikos 118:1335-1342.

Hooper, D. U., et al. 2005. Effects of biodiversity on ecosystem functioning: a consensus of current knowledge. Ecological Monographs 75:3-35.

Huston, M. A. 1997. Hidden treatments in ecological experiments: re-evaluating the ecosystem function of biodiversity. Oecologia 110:449-460.

Hutchinson, G. E. 1959. Homage to Santa Rosalia, or Why are there so many kinds of animals? American Naturalist 93:145159.

Isbell, F., et al. 2011. High plant diversity is needed to maintain ecosystem services. Nature 477:199-202.

Lill, J. T., and R. J. Marquis. 2003. Ecosystem engineering by caterpillars increases insect herbivore diversity on white oak. Ecology 84:682-690.
Loreau, M., and A. Hector. 2001. Partitioning selection and complementarity in biodiversity experiments. Nature 412:7276.

Loreau, M., N. Mouquet, and A. Gonzalez. 2003. Biodiversity as spatial insurance in heterogeneous landscapes. Proceedings of the National Academy of Sciences USA 100:12765-12770.

MacArthur, R. H. 1958. Population ecology of some warblers of northeastern coniferous forests. Ecology 39:599-619.

Naeem, S., and J. P. Wright. 2003. Disentangling biodiversity effects on ecosystem functioning: deriving solutions to a seemingly insurmountable problem. Ecology Letters 6:567579 .

Northfield, T. D., G. B. Snyder, A. R. Ives, and W. E. Snyder. 2010. Niche saturation reveals resource partitioning among consumers. Ecology Letters 13:338-348.

Petchey, O. L. 2003. Integrating methods that investigate how complementarity influences ecosystem functioning. Oikos 101:323-330.

SAS Institute. 2010a. JMP 9.0. SAS Institute, Cary, North Carolina, USA.

SAS Institute. 2010b. SAS 9.0. SAS Institute, Cary, North Carolina, USA.

Schmitz, O. J. 2007. Predator diversity and trophic interactions. Ecology 88:2415-2426.

Silvertown, J., M. E. Dodd, D. J. D. Gowing, and J. O. Mountford. 1999. Hydrologically defined niches reveal a basis for species richness in plant communities. Nature 400:61-63.

Simberloff, D., and W. Boecklen. 1981. Santa Rosalia reconsidered: size ratios and competition. Evolution 35:1206-1228.

Snyder, W. E., G. B. Snyder, D. L. Finke, and C. S. Straub. 2006. Predator biodiversity strengthens herbivore suppression. Ecology Letters 9:789-796.

Steffan, S. A., and W. E. Snyder. 2010. Cascading diversity effects transmitted exclusively by behavioral interactions. Ecology 91:2242-2252.

Straub, C. S., and W. E. Snyder. 2008. Increasing enemy biodiversity strengthens herbivore suppression on two plant species. Ecology 89:1605-1615.

Strong, D. R., L. A. Szyska, and D. S. Simberloff. 1979. Tests of community-wide character displacement against null hypotheses. Evolution 33:897-913.

Takizawa, T., and W. E. Snyder. 2011. Cannibalism and intraguild predation of eggs within a diverse predator assemblage. Environmental Entomology 40:8-14.

Talekar, N. S., and A. M. Shelton. 1993. Management of the diamondback moth. Annual Review of Entomology 38:275301.

Wright, J. P., C. G. Jones, and A. S. Flecker. 2002. An ecosystem engineer, the beaver, increases species richness at the landscape scale. Oecologia 132:96-101.

Zavaleta, E. S., J. R. Pasari, K. B. Hulvey, and G. D. Tilman. 2010. Sustaining multiple ecosystem functions in grassland communities requires higher biodiversity. Proceedings of the National Academy of Sciences USA 107:1443-1446.

\section{Supplemental Material}

\section{Appendix}

Methods related to the field and greenhouse experiments, eight figures showing data from the field and greenhouse experiments, and six tables showing results of the statistical analyses (Ecological Archives E093-189-A1). 